\title{
Mammals of China
}

Edited by Andrew T. Smith and Yan Xie. 2013. Princeton University Press, 41 William Street, Princeton, NJ, USA, 085405237. 396 pages, 24.95 USD, Paper.

This book arrived just before I left for Mongolia. Not quite China, but I thought it would be worth testing in the field. I was not disappointed. Many mammals are shared by both countries. Even the range maps were useful as a south China species was not likely to occur inside its northern neighbour. I saw 12 species of mammal and photographed nine. I was able to confirm my identifications with a government naturalist. So I think this book works well.

It was originally issued as a larger, hard covered book in 2008. I said then "This is a much needed guide and it will be indispensable for naturalists and mammalogists for years to come." This paperback version covers all of China's 558 species of mammals in a handy-sized book. Each species has the English, Chinese (in Chinese characters and transliterated) and scientific name, but the text is all in English. The brief description focuses on the key identification characteristics. The Chinese range is given on a map. The world distribution is given as text - most useful in Mongolia. The creature's natural history tells of its habits, food, habitat, and reproduction.

The artwork is from the 2008 book and is excellent (by Federico Gemma). A comparison of the mammals with which I am most familiar showed the paintings to be accurate in shape and colour. However the reader should be warned that not all the species are illustrated.
For example only eight of the 22 species of Pika are shown. So the written descriptions are critical. The illustrations are next to the text (not in a plates section as in the original book) and this is much more practical for a field book

The range maps are still a little confusing. The authors state "the maps depict the original distribution ... before contraction ... due to anthropogenic factors." Yet they also say "the distribution ... in the most accurate form possible at the present time. "I find these statements a little at odds. What I want is the current distribution, not the historical range. The authors, for reasons they define, use the actual location of each of an accurate record (specimen etc.) as a dot. I would still prefer a best guess given as a shaded zone.

I checked the two errors I noted in the original text. They are still there (for example Savi's pipistrelle occurs in the Mediterranean region of southern Europe, as well as northern Africa, the Middle East, Asia, Mongolia and Japan - not in Northern Europe.)

I still think this is a great book and it is now more portable. I will take on my upcoming visit to China next spring.

ROY JOHN

2193 Emard Crescent, Beacon Hill North, Ottawa, ON, Canada, K1J 6 K5 